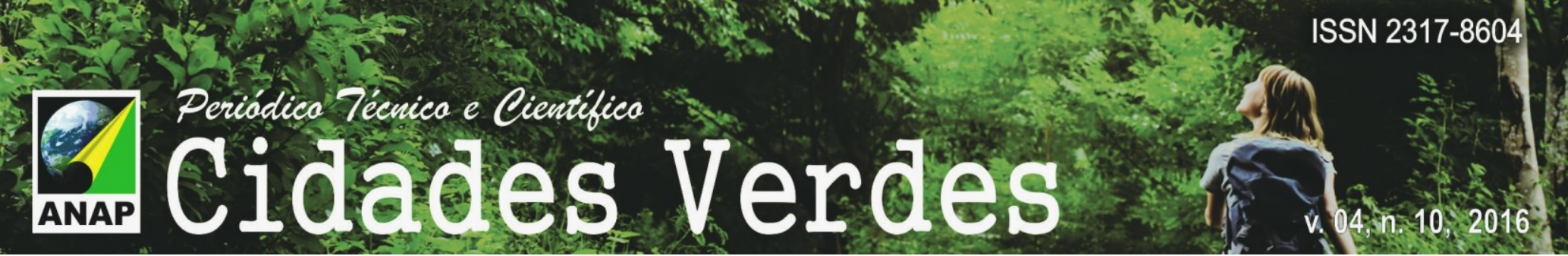

\title{
AVALIAÇÃO DA INSERÇÃO URBANA DE BACIAS DE DETENÇÃO DE ÁGUAS PLUVIAIS EM DOIS CONDOMÍNIOS RESIDENCIAIS NOS MUNICÍPIOS DE ARARAQUARA E SÃO CARLOS, SÃO PAULO - BRASIL
}

Evaluation of Urban Integration in Detention Basin of Rainwater in Two Residential Condominiums in t Municipalities of Araraquara and São Carlos, São Paulo - Brazil

Evaluación de la Inserción Urbana de Dispositivos de Detención de Aguas Pluviales en Dos Condominios Residenciales en los Municipios de Araraquara y São Carlos, São Paulo - Brasil

Carolina Sulzbach Lima Peroni

Mestranda do Programa de Pós-Graduação em Engenharia Urbana, UFSCar, Brasil carolina.peroni@yahoo.com.br

Bernardo Arantes do Nascimento Teixeira Professor Doutor do Programa de Pós-Graduação em Engenharia Urbana, UFSCar, Brasil bernardo@ufscar.br 


\section{RESUMO}

A urbanização acarreta, entre outros aspectos, a alteração do ciclo hidrológico, o desmatamento de matas ciliares e a ocupação de áreas de risco por populações frágeis. Esse cenário atrelado à ineficiência do sistema de drenagem urbana tradicional resulta em inundações mais frequentes e de maior magnitude, ocasionando perdas à população e ao poder público. Dentro desse contexto, as técnicas compensatórias em drenagem urbana desempenham relevante papel na mitigação dos impactos da urbanização sobre o escoamento superficial e a infiltração das águas pluviais. As bacias de detenção, em especial, são as mais frequentes soluções compensatórias aplicadas no Brasil, além de serem únicas no controle de vazões de pico com grandes tempos de retorno. Por essa razão o presente artigo teve como objetivo avaliar duas bacias de detenção implantadas no meio urbano dos municípios de Araraquara (Bacia 1) e São Carlos (Bacia 2), SP, quanto à inserção urbana, manutenção e integração destas unidades com seus entornos. A metodologia adotada para tal avaliação foi composta por visitas in loco, imagens do Google Earth e critérios de avaliação como posição relativa, visibilidade, isolamento, conservação e concentração. Desta forma, observou-se, nos casos estudados, uma forte tendência de se implantar as bacias de detenção distantes e isoladas de seu entorno e voltadas exclusivamente para a função hidrológica, sem a previsão de usos múltiplos que favorecem a ocupação destes espaços pela população e sem uma integração efetiva com o espaço urbano.

PALAVRAS-CHAVE: Drenagem Urbana Sustentável. Bacia de Detenção. Inserção Urbanística.

\section{ABSTRACT}

Urbanization precipitates, among other things, the alteration of the hydrologic cylce, deforastation of riparian forests and the occupancy of hazard areas by fragile communities. This scenario, coupled with the inefficiency of the traditional approach in Brazilian urban drainage, results in flooding with increasing frequency and magnitude, leading to losses to the population and to the public authorities. Within this context, the compensatory techniques in urban drainage have a leading role in the mitigation of the environmental impacts of urbanization in surface runoff and the infiltration of rainwater to the ground. The detention basins, in particular, are the most prevailing compensatory solution used in Brazil, besides being unique in the control of peak flows with great return periods. Therefore, this article had as its main goal to examine two detention basins implemented in the urban areas in the municipalities of Araraquara (Basin 1) and São Carlos (Basin 2), SP, in terms of urban integration, upkeep and the integration of these units with their surrounding communities. The methodology adopted for such evaluation consisted of in loco visits, Google Earth images and evaluation criteria such as relative position, visibility, conservation and concentration. Thus, it was observed that, in the cases studied, there was a strong tendency to implement detention basins that were isolated and far from their surrounding communities and dedicated exclusively to the hydrologic role, without predicting multiple uses that favor the occupancy of these areas by the population and without an effective integration of the urban surroundings.

KEY WORDS: Sustainable Urban Drainage. Detention Basin. Urban Insertion.

\section{RESUMEN}

La urbanización acarrea, entre otros aspectos, la alteración del ciclo hidrológico, la deforestación de los bosques ribereños y la ocupación de áreas de riesgo por poblaciones frágiles. Ese escenario, vinculado a la ineficiencia de los sistemas de drenaje tradicionales resulta en inundaciones más frecuentes e de mayor magnitud, ocasionando pérdidas a la población y al poder público. Dentro de este contexto, las técnicas compensatorias en drenaje urbano desempeñan un papel relevante en la mitigación de los impactos de la urbanización sobre la escorrentía superficial y la infiltración de las aguas pluviales. Los dispositivos de detención, en especial, son los más frecuentemente implementados en Brasil, además de ser únicos en el control de caudales pico con grandes periodos de retorno. Por esta razón, el presente artículo tiene como objetivo evaluar dos dispositivos de detención implantados en el medio urbano de los municipios de Araraquara (Dispositivo 1) y San Carlos (Dispositivo 2), San Paulo - Brasil, en cuanto a su inserción urbana, manutención e integración de estas unidades con sus entornos. La metodología adoptada para tal evaluación fue compuesta por visitas "in situ", imágenes de Google Earth y criterios de evaluación como posición relativa, visibilidad, aislamiento, conservación y concentración. De esta forma se observó en los casos estudiados, una fuerte tendencia de implantarse dispositivos de detención alejados y aislados de su entorno, e implantados exclusivamente para fines hidrológicos, sin la previsión de usos múltiples que favorecen la ocupación de estos espacios por la población y sin una integración efectiva con el espacio urbano.

PALABRAS-CLAVES: Drenaje Urbano Sostenible. Dispositivo de Detención. Inserción Urbana. 


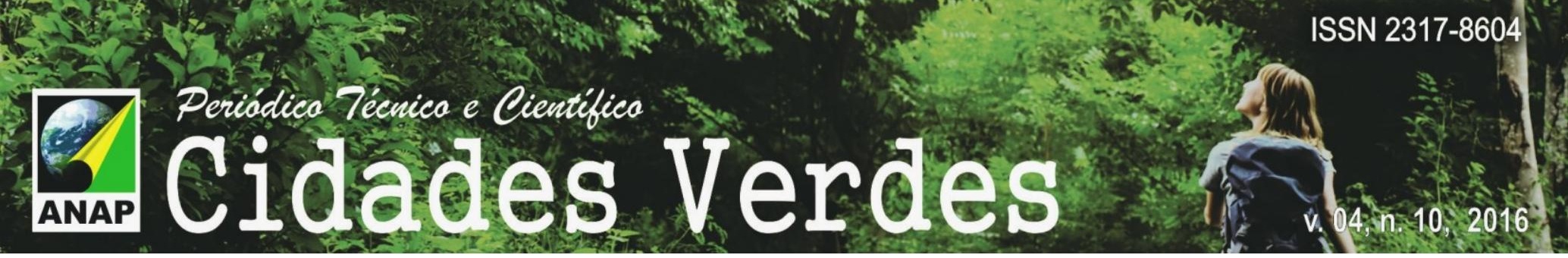

\section{INTRODUÇÃO}

A população urbana mundial, no início do século $X X$, representava apenas $15 \%$ da população mundial, se configurando como amplamente rural (TUCCI, 2015). Atualmente, cerca de $54 \%$ da população mundial reside em áreas urbanas, uma porcentagem que deve aumentar para $66 \%$ em 2050, incrementando mais de 2,5 bilhões de pessoas para populações urbanas (UNRIC, 2016).

Segundo TUCCI (2015) o Brasil teve um crescimento significativo de sua população urbana, ao longo das últimas décadas. Seu processo de urbanização acelerado ocorreu após a década de 60, e junto com ele uma crescente população urbana sem acesso a infraestruturas de saneamento, transportes, educação e saúde; as quais, em muitos casos, se sobrecarregaram com a alta demanda atrelada a ausência de investimentos e instrumentos legais proporcionais ao crescimento populacional (CHRISTOFIDIS, 2010).

Segundo Maricato (2008), o crescimento urbano brasileiro está acompanhado de muitos aspectos negativos, como a ocupação de áreas ambientalmente frágeis, "como beira de rios, de córregos, de lagoas, mangues, reservatórios de água potável, dunas, áreas de matas e florestas, encostas instáveis, várzeas etc"; assim como de altos índices de impermeabilização do solo, desmatamento e desenvolvimento indisciplinado; consequências que interferem diretamente nos fenômenos do ciclo hidrológico, em especial na infiltração e escoamento superficial direto das águas pluviais (PORTO et al, 2015).

A impermeabilização do solo e supressão da vegetação são fatores relevantes para a alteração do ciclo hidrológico e intensificação da ocorrência de inundações em área urbana. A água que antes infiltrava passa a escoar por galerias, aumentando o escoamento superficial. Já o volume que escoava lentamente pela superfície do solo natural e ficava retido pela vegetação, após a urbanização, passar a escoar nos canais, que requerem maior capacidade de escoamento (TUCCl, 2015).

Assim, fica evidente a ineficiência dos preceitos higienistas, estabelecidos no século XIX e seguidos até os dias de hoje na concepção do sistema convencional de drenagem urbana, cujo objetivo é a drenagem e evacuação rápida das águas pluviais, por meio de galerias. É necessária uma compreensão mais integrada da área urbana e das relações entre os sistemas que a compõe, com a atuação intensa do poder público (PORTO et al, 2015) para a concepção e implantação dos sistemas de drenagem urbana de maneira sustentável.

Essa visão mais ampla e integrada é preconizada na concepção das técnicas compensatórias em drenagem urbana, desenvolvidas a partir dos anos 1970, com o intuito de minimizar os impactos da urbanização sobre os processos hidrológicos, a partir da valorização da presença da água no ambiente urbano e da integração urbanística destas técnicas, com a criação de espaços de convivência e contemplação para a população. 


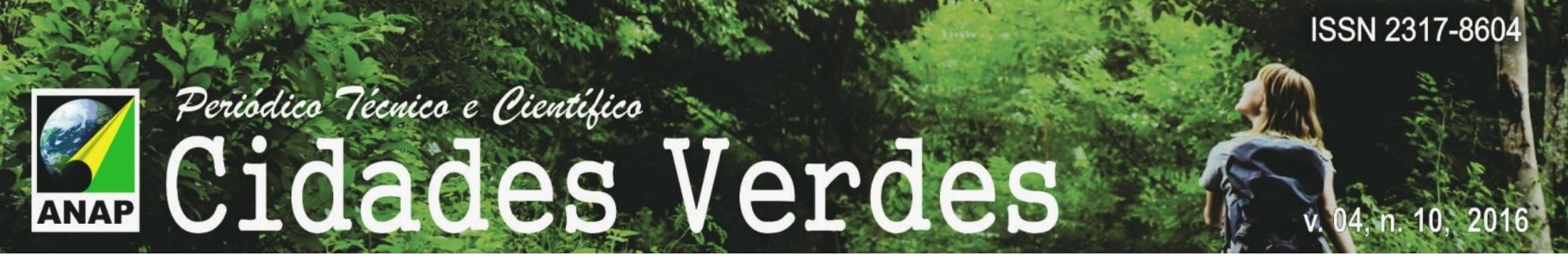

2 OBJETIVO

O presente artigo tem como objetivo avaliar duas bacias de detenção, localizadas no meio urbano dos municípios de Araraquara e São Carlos, SP, sob os aspectos físicos, ambientais, sanitários e de inserção urbanística; de maneira a retratar como estas técnicas compensatórias em drenagem urbana estão sendo inseridas no contexto urbano, bem como sua manutenção e integração com seu entorno.

\section{REPENSANDO O MANEJO DE ÁGUAS PLUVIAIS URBANAS}

O modelo de urbanização implementado no Brasil tem se mostrado, muitas vezes, como um processo ineficiente e precário. Porém várias tentativas de um melhor convívio entre o ser humano e a natureza vêm provendo um novo paradigma, de urbanização de menor impacto e "renaturalização", conceito este que pode ser entendido "como qualquer medida de reversão dos impactos da urbanização tradicional". Este ainda preconiza áreas urbanas, em especial, no tocante as enchentes urbanas, viabilizando o desenvolvimento urbano sustentável nas áreas suscetíveis a estes eventos, prioritariamente (CARVALHO e BRAGA, s.d.).

O conceito de renaturalizar os centros urbanos vai ao encontro das novas abordagens realizadas no âmbito da drenagem urbana sustentável, que defendem a manutenção das condições naturais para garantir a minimização dos efeitos da impermeabilização, da susceptibilidade de populações residentes em áreas de risco e da qualidade e quantidade dos recursos hídricos presentes no meio urbano.

\subsection{DRENAGEM URBANA SUSTENTÁVEL}

O termo Drenagem Urbana Sustentável é recente e engloba um conjunto variado de medidas estruturais e não estruturais, que visam compensar os impactos da urbanização sobre os fenômenos do ciclo hidrológico em área urbana. Esse modelo sustentável preconiza o aumento de áreas permeáveis, redução de picos de cheia, aumento do tempo de concentração da água pluvial e manutenção da qualidade das águas, garantindo uma melhora no meio ambiente e meio urbano (CHRISTOFIDIS, 2010).

Os últimos 30 anos se caracterizaram por relevantes discussões a cerca do estilo de desenvolvimento econômico adotado, resultando na proposição do desenvolvimento sustentável, um novo modelo de crescimento econômico, que prevê a integração equilibrada entre sociedade, economia e meio ambiente. A associação, portanto, do termo sustentabilidade com a drenagem urbana, vem contribuir para uma melhor integração deste sistema à dinâmica urbana, reconhecendo a complexidade das relações existentes entre o meio natural, urbano e a sociedade (POMPÊO, 2000).

Segundo Christofidis (2010), na década de 70, nos países desenvolvidos, novas propostas para o manejo das águas pluviais foram realizadas, tais como modelos fundamentados em Melhores Práticas de Gestão, ou Best Managment Practices - BMPs e desenvolvimento de 


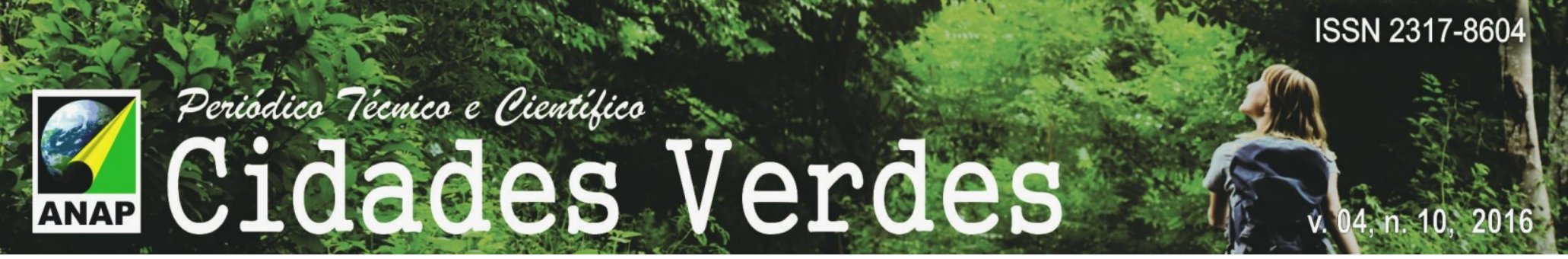

baixo impacto ou Low Impact Development - LID, incorporando grande avanço nos procedimentos de planejamento e gestão das águas pluviais.

O Quadro 1 apresenta um comparativo entre o sistema de drenagem urbana tradicional com as práticas alternativas impulsionadas desde 1970.

Quadro 1: Comparação entre Drenagem Urbana Tradicional e Sustentável

\begin{tabular}{|c|c|}
\hline Drenagem Urbana Tradicional & Soluções Alternativas \\
\hline Drenagem rápida das águas pluviais. & $\begin{array}{l}\text { Favorecimento à infiltração, ao armazenamento e ao } \\
\text { aumento do tempo de percurso do escoamento. }\end{array}$ \\
\hline $\begin{array}{l}\text { Redes subterrâneas, canalização de cursos d'água } \\
\text { naturais. }\end{array}$ & $\begin{array}{l}\text { Valorização da presença da água na cidade, busca de } \\
\text { menor interferência sobre o sistema natural de } \\
\text { drenagem. }\end{array}$ \\
\hline Associação do sistema de drenagem ao sistema viário. & $\begin{array}{l}\text { Desenvolvimento de soluções técnicas multifuncionais, } \\
\text { combinando o sistema de drenagem com a implantação } \\
\text { de áreas verdes, terrenos de esporte, parques lineares, } \\
\text { etc. }\end{array}$ \\
\hline $\begin{array}{l}\text { Sistema de drenagem gravitacional, não controlado, } \\
\text { configuração fixa da rede de drenagem. }\end{array}$ & $\begin{array}{l}\text { Sistema de drenagem controlado, possibilidade de } \\
\text { alteração na configuração da rede de drenagem. }\end{array}$ \\
\hline $\begin{array}{l}\text { Concepção e dimensionamento segundo um nível único } \\
\text { de risco de inundação pré-estabelecido, para atender a } \\
\text { um único objetivo. }\end{array}$ & $\begin{array}{l}\text { Concepção e dimensionamento segundo diferentes } \\
\text { níveis de risco de inundação, para atender a objetivos } \\
\text { diferenciados. }\end{array}$ \\
\hline $\begin{array}{l}\text { Não previsão e inoperância em face de eventos de } \\
\text { tempos de retorno superiores aos de projeto. }\end{array}$ & $\begin{array}{l}\text { Avaliação do funcionamento do sistema para eventos de } \\
\text { tempos de retorno superiores aos de projeto, gestão do } \\
\text { risco de inundação. }\end{array}$ \\
\hline $\begin{array}{l}\text { Ênfase na garantia de condições de saúde pública e de } \\
\text { conforto no meio urbano; } \\
\text { Despreocupação com os impactos da urbanização sobre } \\
\text { os meios receptores. }\end{array}$ & $\begin{array}{l}\text { Preocupação com a garantia de condições adequadas de } \\
\text { saúde pública e conforto no meio urbano e de redução } \\
\text { dos impactos da urbanização sobre os meios receptores. }\end{array}$ \\
\hline
\end{tabular}

Fonte: NASCIMENTO et al, 1999

Por fim, a drenagem urbana sustentável, assim como o sistema tradicional, compreende a micro e macrodrenagem, porém agora de maneira mais integrada ao meio urbano, buscando complementar estas estruturas com soluções compensatórias que favoreçam a valorização da água em meio urbano e a criação de áreas verdes e espaços de convivência, garantindo à população maior segurança quanto às inundações e locais de recreação e lazer.

\subsection{TÉCNICAS COMPENSATÓRIAS EM DRENAGEM URBANA}

Desde os anos 1970, vêm sendo desenvolvidas Técnicas Compensatórias (TC) de drenagem em diferentes concepções quanto ao porte e localização das estruturas -, sobretudo na Europa e na América do Norte. $\mathrm{O}$ objetivo das mesmas é de compensar ou minimizar os impactos da urbanização sobre o ciclo hidrológico urbano, agregando benefícios à qualidade de vida da população e a preservação do meio ambiente (BAPTISTA et al, 2015).

No princípio, as TC buscavam apenas o amortecimento das vazões por meio de estruturas de armazenamento ou de infiltração das águas pluviais, promovendo redução do escoamento 


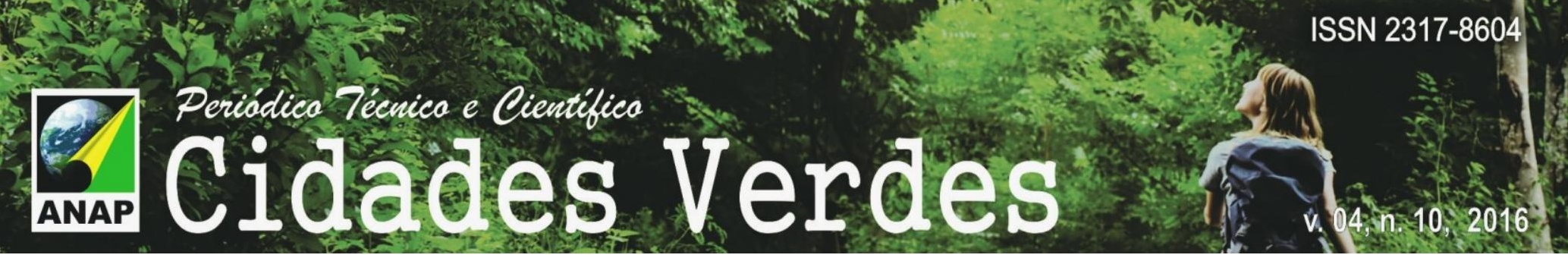

superficial. Com ganho de experiência na aplicação destas técnicas, observou-se que a poluição de origem pluvial também poderia ser reduzida a partir destas soluções (RIGHETTO, 2009).

No Brasil, o emprego das bacias de detenção é a maneira mais frequente de aplicação de TC. Sua utilização se intensificou a partir dos anos 90, principalmente nas regiões metropolitanas de Porto Alegre, Curitiba, São Paulo e Belo Horizonte, com o principal objetivo de amortecimento de cheias, já que são únicas no controle de vazões de pico com tempos de retorno grande, de até 100 anos, característica primordial para minimizar os impactos da urbanização sobre as vazões e velocidades do escoamento superficial (BAPTISTA et al, 2015).

Segundo Baptista et al (2015) estas bacias são estruturas de armazenamento temporário e/ou de infiltração das águas pluviais, denominado de volume de espera, compostas por estrutura de controle de saída e vertedor de emergência. Elas têm como função controlar as inundações pelo amortecimento de cheias em meio urbano, reduzir o volume de escoamento superficial pelo armazenamento e infiltração das águas pluviais e reduzir a poluição difusa.

Do ponto de vista urbanístico, Baptista et al (2015) ressalva ainda que, atualmente, novos esforços vêm sendo realizados para melhorar a integração destas estruturas com o projeto urbanístico local, vislumbrando usos múltiplos, como áreas de lazer e prática de esportes, áreas verdes, praças, jardins etc, em conjunto com a função hidrológica. Porém são necessárias ações de saneamento, manutenção e limpeza para garantir a viabilidade desta combinação, a qual inclusive já é comprovada por vários estudos de casos positivos.

De acordo com Cruz et al (2001), as bacias de detenção ainda são implantadas apenas para desempenhar sua função hidrológica, não estando bem integradas com o espaço urbano, embora alguns municípios estejam se esforçando, como pode ser visto em Porto Alegre (Figura 1), São Paulo (Figura 2) e Belo Horizonte (Figura 3). Em vários países a implantação de dispositivos de infiltração e/ou amortecimento têm sido promissores tanto do ponto de vista hidrológico quanto paisagístico/urbanístico, bem como de convivência com a população (Figuras 4 e 5).

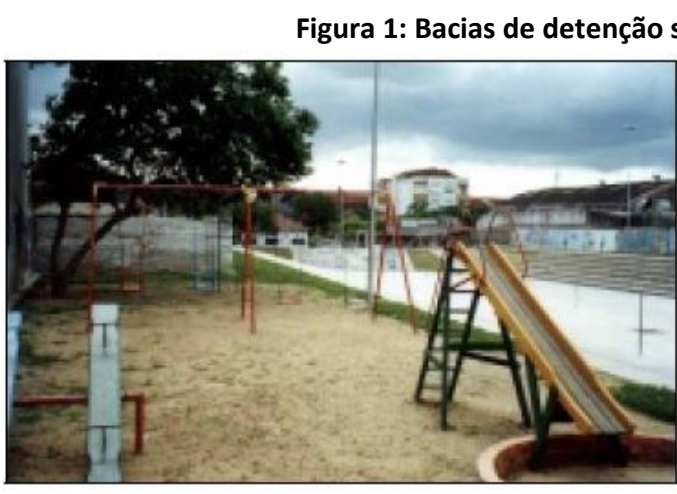

Fonte: CRUZ et al, 2001

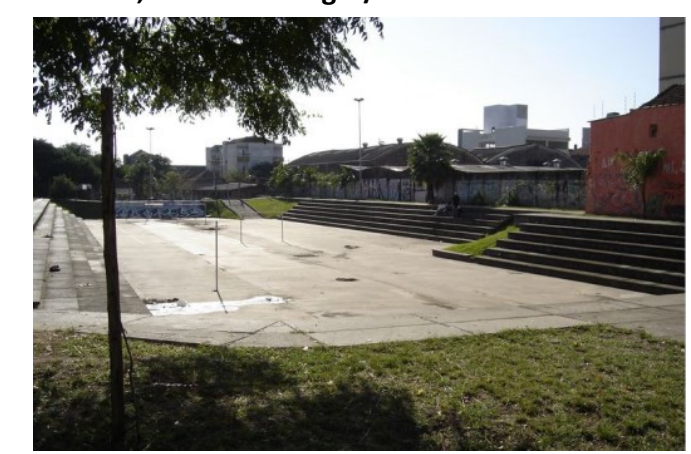

Fonte: PORTO ALEGRE, 2016 


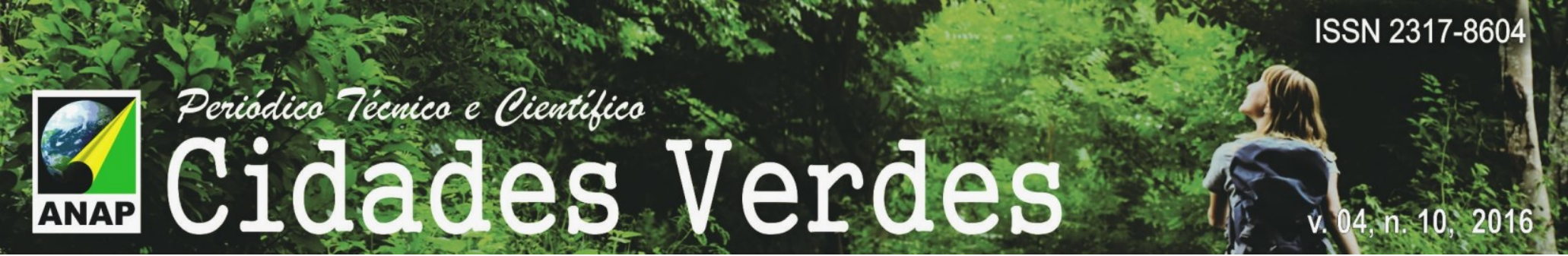

\subsection{ASPECTOS GERAIS DAS ÁREAS DE ESTUDO}

As áreas de estudo do presente artigo são duas bacias de detenção inseridas no meio urbano dos municípios de Araraquara (Bacia 1) e São Carlos (Bacia 2), SP, uma em cada cidade, conforme apresentado nas Imagens 1 e 2.



Fonte: Adaptado de GOOGLE EARTH, 2016



Fonte: Adaptado de GOOGLE EARTH, 2016 


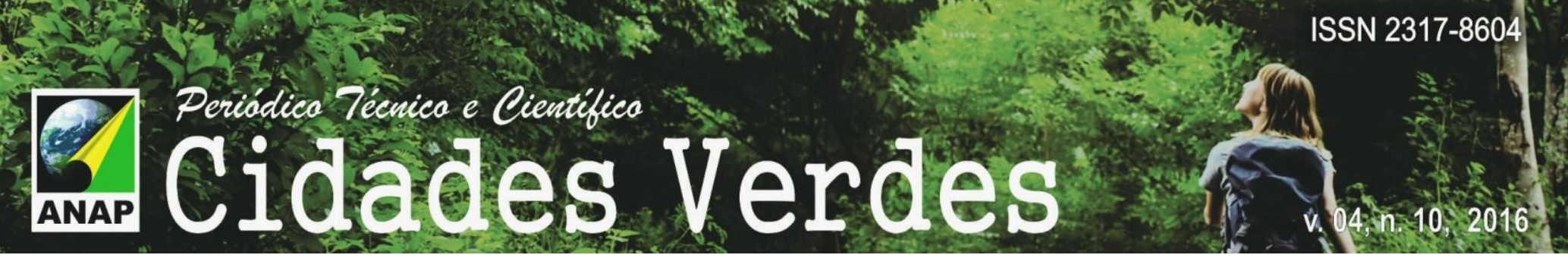

A Bacia 1 está localizada na Avenida Rosa D'Ângelo Merlos, próximo ao Condomínio Portal das Tipuanas, em Araraquara/SP; à margem esquerda do Ribeirão das Cruzes, manancial superficial do município, e a montante do ponto de captação de água. De acordo com o Plano Diretor de Desenvolvimento e Política Ambiental de Araraquara - PDDPA, instituído pela Lei Complementar no 850/2014, a área de estudo (Bacia 1) está inserida na ZOPRE-APRM (Zonas Predominantemente Residenciais - Áreas de Proteção de Mananciais), onde é prevista o uso residencial com densidades construtivas e populacionais variáveis, classificação viária local e diversificação tipológica; além da proteção de manancial para abastecimento público, recuperação, conservação e proteção da mata ciliar, agroecologia e assentamentos sustentáveis, agricultura orgânica familiar e manejo sustentável.

A Bacia 2, por sua vez, está inserida nos limites do Condomínio Parque Eco-Esportivo Damha, em São Carlos/SP, entre a Rodovia Eng. Tales de Lorena Peixoto Junior e a margem direita do Córrego da Jararaca. Segundo o Plano Diretor do Município de São Carlos, estabelecido pela Lei no 13.691/2005, a Bacia 2 está inserida na Zona 4A, subdivisão da Zona 4 (zona de regulamentação e ocupação controlada), área que tende à expansão urbana, mas com usos diversificados que configurem a transição entre o meio rural e o meio urbano.

\subsection{CRITÉRIOS DE AVALIAÇÃO}

Para a avaliação da inserção urbana das Bacias 1 e 2, foram adotados critérios que possibilitassem caracterizar pontos relevantes das unidades a partir da observação visual das mesmas.

Assim, os critérios de avaliação utilizados para as áreas de estudo foram:

- Posição Relativa: indica a posição da bacia de detenção em relação ao condomínio a que estão interligadas, sendo classificadas em "dentro" ou "fora", conforme sua localização quanto aos limites físicos do empreendimento (em geral concretizado na forma de muro ou cerca);

- Visibilidade: indica se as bacias podem ser visualizadas a partir do nível do solo por pessoas presentes no seu entorno, sendo essa visibilidade classificada em "alta", "média" e "baixa";

- Isolamento: indica se existem estruturas que permitam ou impeçam a entrada e o acesso às bacias, sendo classificadas em "totalmente aberta", "parcialmente aberta" ou "totalmente fechada";

- Conservação: trata sobre o estado de conservação das bacias de detenção, com vista a analisar a presença de resíduos sólidos, lâmina d'água, presença de animais e/ou vetores, e vegetação alta, demonstrando ausência ou não de manutenção. Nesse critério as bacias são classificadas em "adequada", "parcialmente adequada" ou "inadequada";

- Funcionalidade: estabelece quais funções são atribuídas às bacias de detenção, de maneira a analisar se são previstos ou adotados outros usos para a área. Assim, a funcionalidade pode ser classificada como "somente hidrológica" ou "multifuncionais"; 




- Concentração: retrata se a bacia de detenção é uma alternativa única e concentrada ou se há várias unidades, sendo classificadas em "bacia única" ou "várias bacias".

\section{RESULTADOS E DISCUSSÕES}

Por meio de visitas in loco foi possível realizar o acervo fotográfico da bacia de detenção de cada município, possibilitando registrar condições importantes para análise da localização das unidades, estado de conservação, facilidade ou dificuldade de acesso às estruturas, visibilidade, concentração e, por fim, multiuso das bacias.

\section{- Bacia 1}

No dia 09 de julho de 2016, foi realizado o primeiro acervo fotográfico da bacia de detenção localizada em Araraquara/SP, denominada de Bacia 1, em um período de estiagem e dia ensolarado (Fotos 1 a 8 ).

Durante a visita in loco foi observada que a Bacia 1 está localizada fora dos limites do condomínio e distante da entrada do empreendimento. Atualmente, é possível visualizar a bacia de detenção no acesso ao conjunto de condomínio presentes na região, porém essa situação deve ser revertida já que está sendo realizado o reflorestamento no entorno da Bacia 1, o que poderá amenizar o impacto visual da referida estrutura (Fotos 1 e 2).

Foto 1: Bacia 1 - Reflorestamento no entorno da Unidade (Vista 1)



Fonte: Autora, 09-07-2016
Foto 2: Bacia 1 - Reflorestamento no entorno da Unidade (Vista 2)

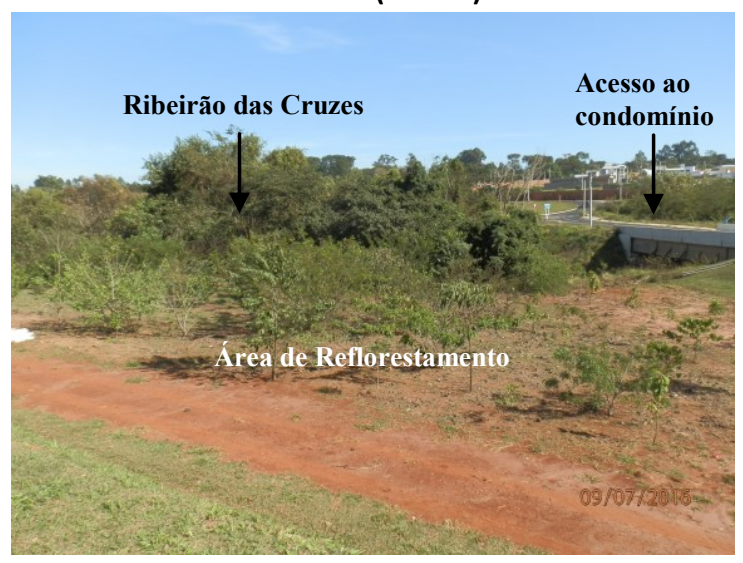

Fonte: Autora, 09-07-2016

A Bacia 1 é totalmente cercada com alambrado (Foto 3) e sua entrada permanece com corrente e cadeado, impedindo o acesso à unidade, exceto com a permissão dos responsáveis (Foto 4). 


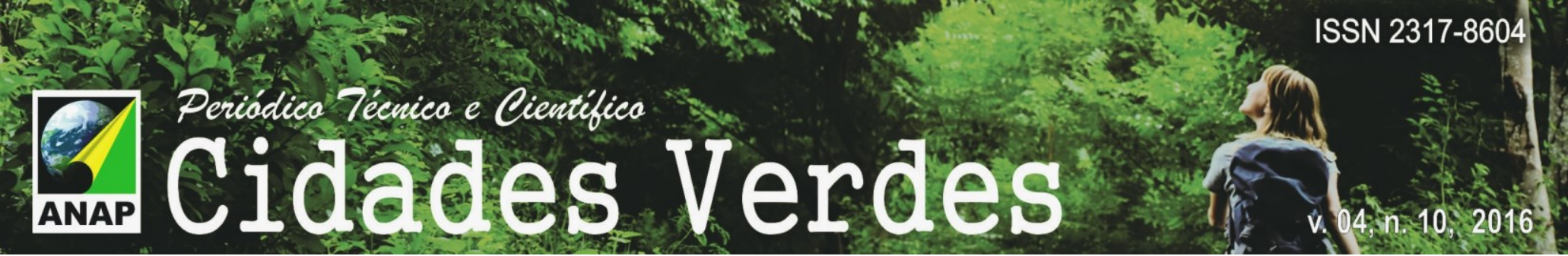

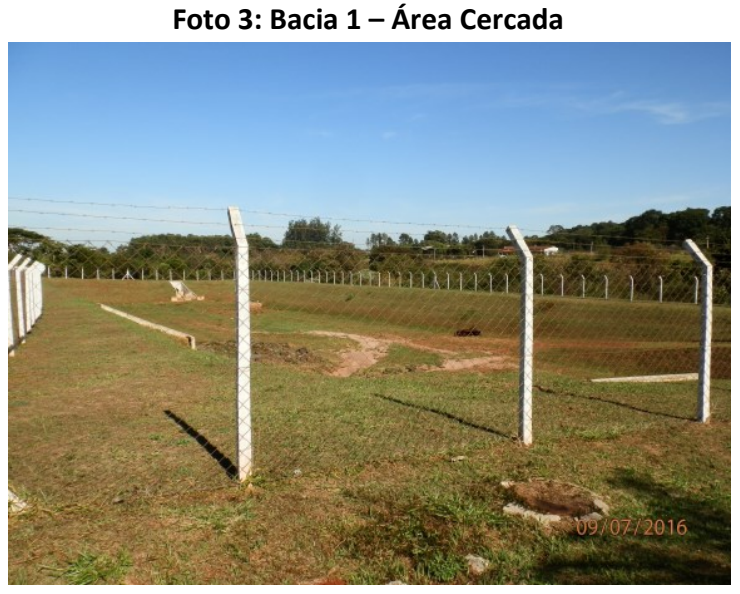

Fonte: Autora, 09-07-2016

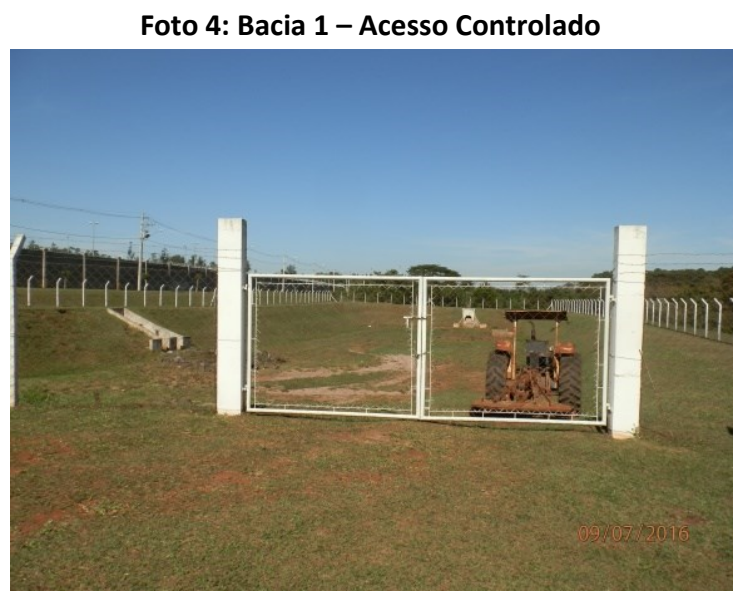

Fonte: Autora, 09-07-2016

É possível observar nas Fotos 4 e 5 a presença de um pequeno trator dentro da bacia de detenção, o qual deve ser utilizado para a manutenção da área e de seu arredor, totalmente, coberto por vegetação gramínea. Inclusive o estado de conservação desta bacia estava adequado, durante as visitas, como pode ser observado em todo acervo fotográfico, não havendo a presença de resíduos sólidos, lâmina d'água e vegetação alta, fatores que poderiam interferir na função hidrológica desta unidade.

Foto 5: Bacia 1 - Equipamento para manutenção

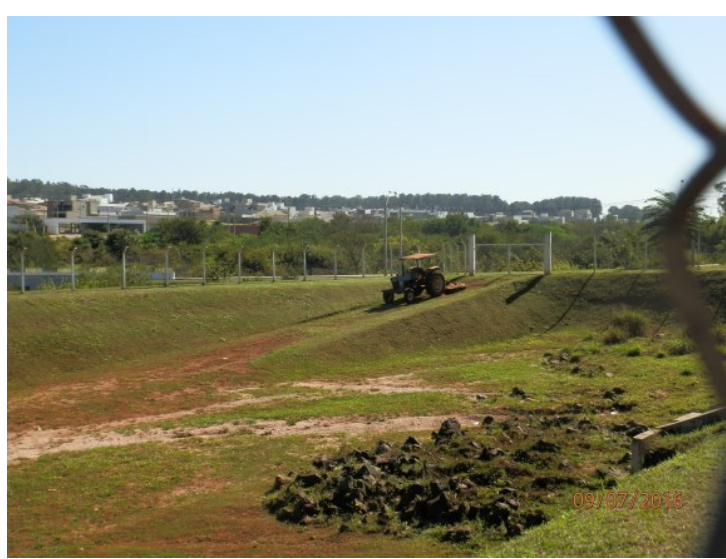

Fonte: Autora, 09-07-2016
Foto 6: Bacia 1 - Estruturas de entrada e saída de água

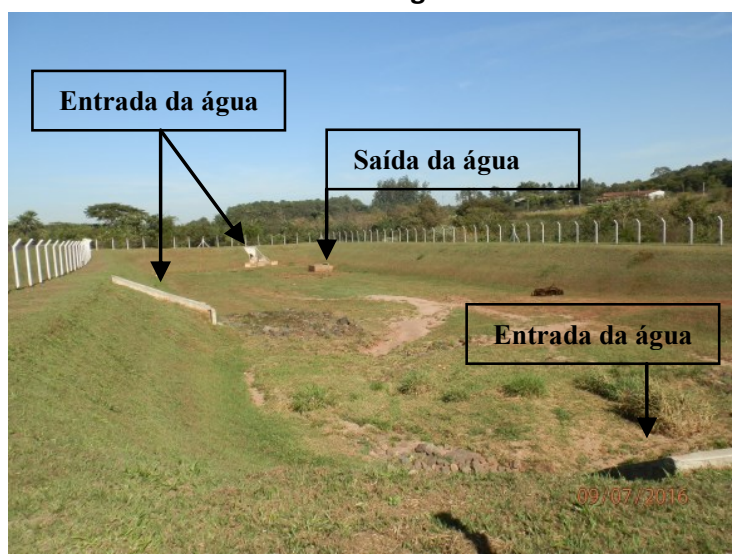

Fonte: Autora, 09-07-2016

Na Foto 6 é possível observar as estruturas de entrada e de saída da bacia de detenção, em concreto. Ao todo são três estruturas de entrada de água e uma de saída. Cada estrutura de entrada da água possui dissipadores de energia, conforme demonstrado nas Fotos 7 e 8, com uso de pedras (Dissipador 1 ) e de peças de concreto (Dissipador 2). 




Foto 7: Bacia 1 - Dissipador 1 de energia na estruturas de entrada de água

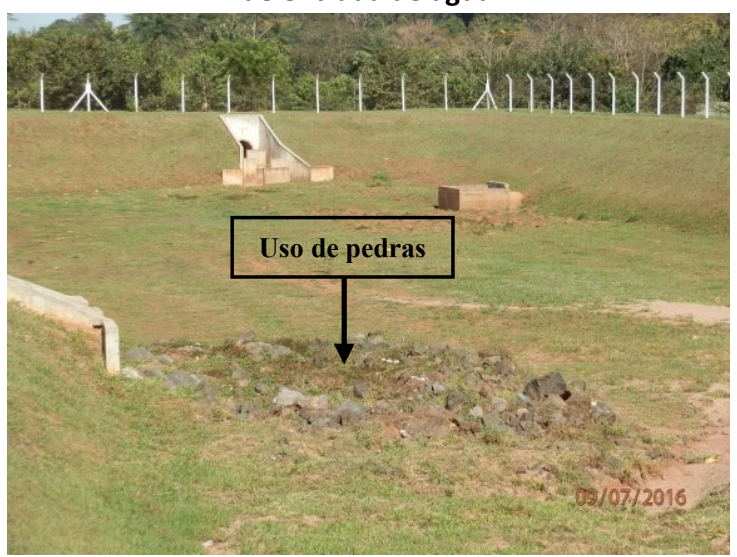

Fonte: Autora, 09-07-2016
Foto 8: Bacia 1 - Dissipador 2 de energia na estrutura de entrada de água

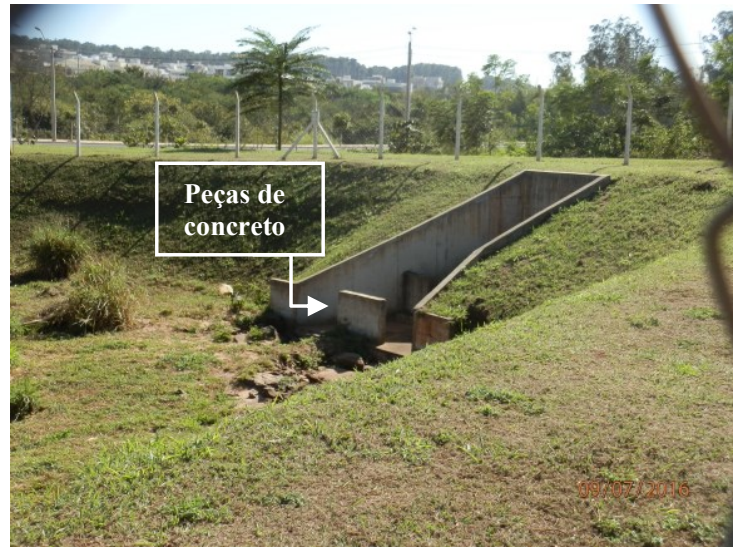

Fonte: Autora, 09-07-2016

\section{- Bacia 2}

No dia 16 de agosto de 2016, foi realizado o acervo fotográfico da bacia de detenção localizada no Condomínio Damha em São Carlos/SP. Neste dia, o tempo estava parcialmente nublado e dias anteriores à visita, houve a ocorrência de precipitações (Fotos 9 a 16).

Foi possível identificar, durante a visita in loco, que a Bacia 2 está localizada dentro dos limites físicos do Condomínio Damha, sendo seu acesso exclusivo por este, porém está afastada da área destinada às residências e da maioria dos equipamentos urbanos (Imagem 2 ).

A Bacia 2 é totalmente cercada por grades e sua entrada dispõe de portão que pode ser trancado, embora estivesse aberto no momento da visita.

Foto 9: Bacia 2 - Vista Geral

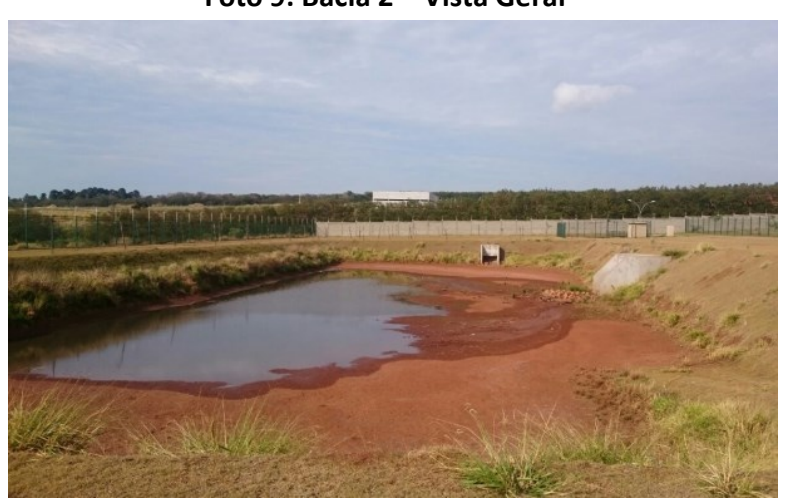

Fonte: Autora, 16-08-16
Foto 10: Bacia 2 - Área Cercada

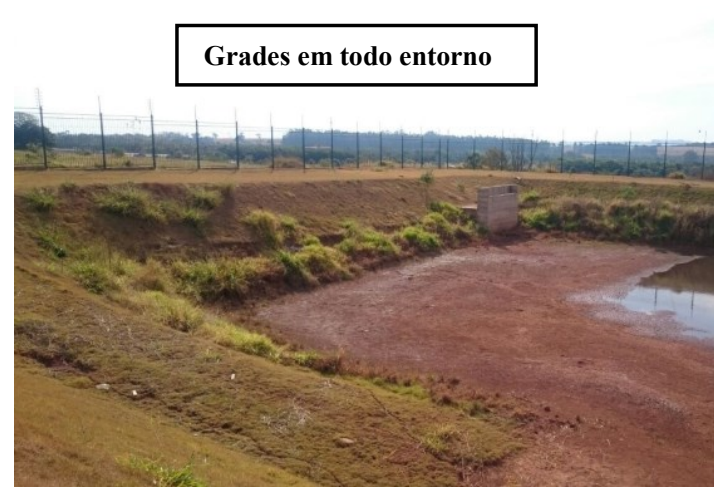

Fonte: Autora, 16-08-2016

Quanto ao estado de conservação desta unidade, observou-se vegetação em alguns pontos da Bacia 2 (Fotos 9 e 10), sendo que a unidade não apresentava cobertura gramínea no fundo. Em termos de limpeza, observou-se a presença de resíduos sólidos, em especial materiais plásticos (Foto 11), ainda que em pequena quantidade. 


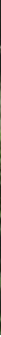

Foto 11: Bacia 2 - Resíduos sólidos

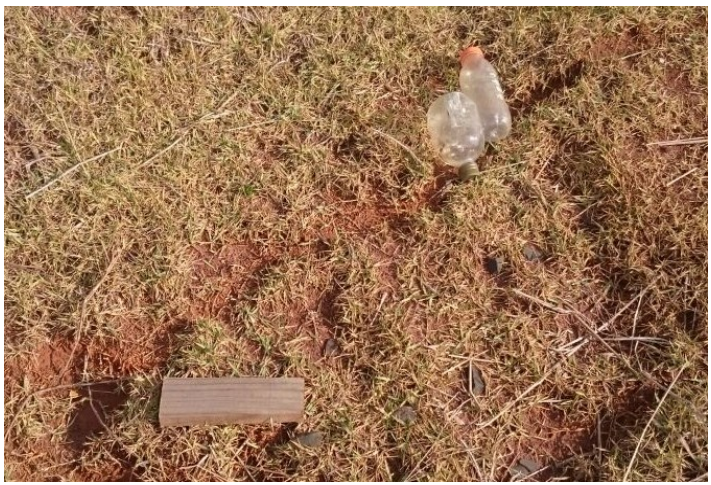

Fonte: Autora, 16-08-2016
Foto 12: Bacia 2 - Lâmina d'Água

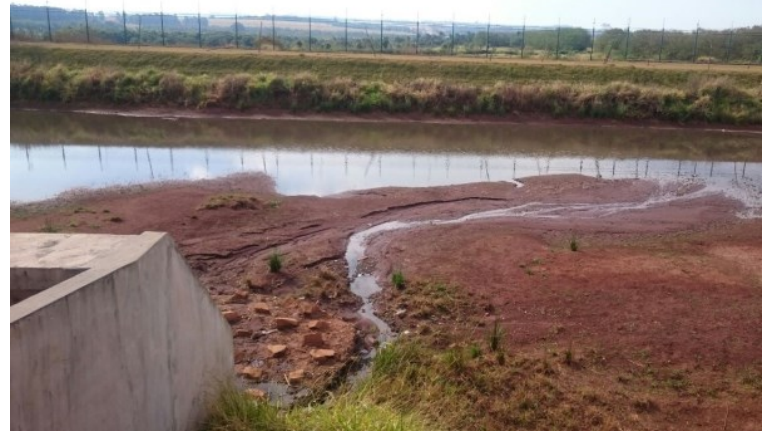

Fonte: Autora, 16-08-2016

Como descrito anteriormente, em dias anteriores à visita ocorreram precipitações no município de São Carlos, o que justifica a presença de uma lâmina d'água ocupando parte da superfície do fundo (Fotos 9 e 12). Isto indica, por um lado, que o nivelamento do fundo não permite o esvaziamento total apenas por escoamento pela estrutura de saída e, por outro, que a infiltração no solo também não é suficiente para tal esvaziamento. Outra observação foi a presença de sedimentos no fundo da unidade, próxima a entrada de água, indicando o carreamento de sólidos e, por conseguinte, assoreamento de alguns trechos da Bacia 2 (Fotos 12 e 13).

Foto 13: Bacia 2 - Sedimentos no fundo

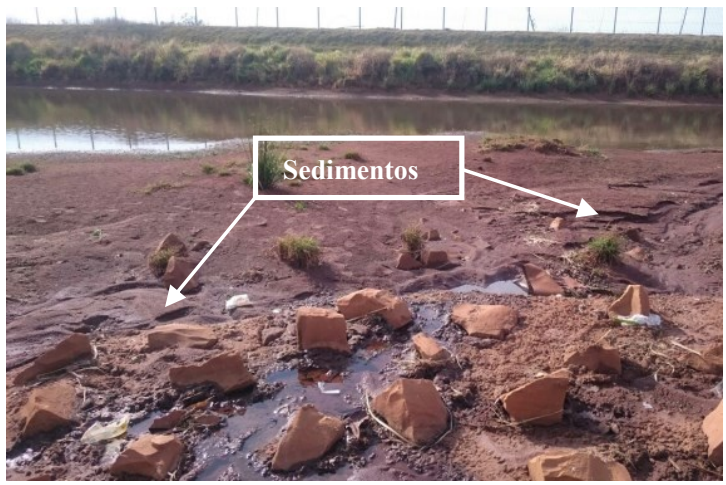

Fonte: Autora, 16-08-16
Foto 14: Bacia 2 - Estruturas de Entrada de Água



Fonte: Autora, 16-08-2016

Na Foto 14 são apresentadas as estruturas de entrada da água na Bacia 2, construídas em concreto e compostas por dissipadores de energia com peças de concreto e com o uso de pedras (Foto 15). Na Foto 16 é indicada a estrutura de saída de água da bacia de detenção, cuja tubulação de saída não foi possível visualizar nem registrar para o presente acervo fotográfico durante a visita, mas está localizada no fundo desta estrutura, no nível do solo. 




cada unidade, estando em melhor estado de conservação a Bacia 1, localizada fora dos limites físicos do condomínio. O estado de conservação das unidades é fator relevante para o bom funcionamento das bacias de detenção durante e após a precipitação. A presença de resíduos sólidos, sedimentos e vegetação pode interferir no esvaziamento das bacias, comprometendo, principalmente, o desempenho das estruturas de saída e podendo acarretar danos no seu entorno.

Observou-se ainda que as bacias de detenção são implantadas apenas para desempenhar sua função hidrológica, não estando integradas com seu entorno nem sendo utilizadas para outros usos, como por exemplo, áreas de recreação, parques e áreas verdes, mesmo sendo esta uma prática com forte tendência mundial e com iniciativas brasileiras bem sucedidas.

As bacias estudadas apresentaram ainda em comum o fato de serem inseridas distantes do convívio dos condôminos e de estarem delimitadas por alambrados (Bacia 1) ou grades (Bacia 2), criando espaços que podem ser interpretados pelos moradores como uma área sem finalidade, já que não agregam embelezamento à paisagem nem usos múltiplos que permitam a entrada e acesso as mesmas.

Por fim, conclui-se que, dentro dos contextos urbanos estudados, as bacias de detenção ainda estão sendo encaradas apenas como dispositivos de detenção, implantados isoladamente de seu entorno, requerendo, como demais estruturas do condomínio, manutenção e limpeza. É fato que a obrigatoriedade de implantação destas bacias (exigência em alguns municípios brasileiros) demonstra um grande avanço no âmbito do manejo de águas pluviais, porém o pouco interesse e incentivo à integração urbana das mesmas é um entrave para a consolidação desta prática, reduzindo as oportunidades de um ambiente urbano mais integrado às necessidades de toda população.

\section{AGRADECIMENTOS}

À Coordenação de Aperfeiçoamento de Pessoal de Nível Superior (CAPES) pela concessão de bolsa de estudo de Mestrado.

\section{REFERÊNCIAS BIBLIOGRÁFICAS}

BAPTISTA, M.; NASCIMENTO, N.; BARRAUD, S. Técnicas Compensatórias em Drenagem Urbana. Porto Alegre: $A B R H$, 2015. 2a Edição, 318 p.

BELO HORIZONTE. Prefeitura Municipal. Parque Ecológico Primeiro de Maio. Disponível em: <http://www.belohorizonte.mg.gov.br/local/entretenimento-cultura/parque-praca/parque-ecologico-primeiro-demaio>. Acesso em: 29 ago. 2016.

CARVALHO, P. F.; BRAGA, R. Da Negação à Reafirmação da Natureza na Cidade: o conceito de "renaturalização" como suporte à política urbana. Rio Claro, s.d.

CHRISTOFIDIS, H. V. Drenagem Urbana Sustentável: Análise do uso do Retrofit. Brasília. Dissertação (Mestrado em Desenvolvimento Sustentável) - Universidade de Brasília, 2010. 


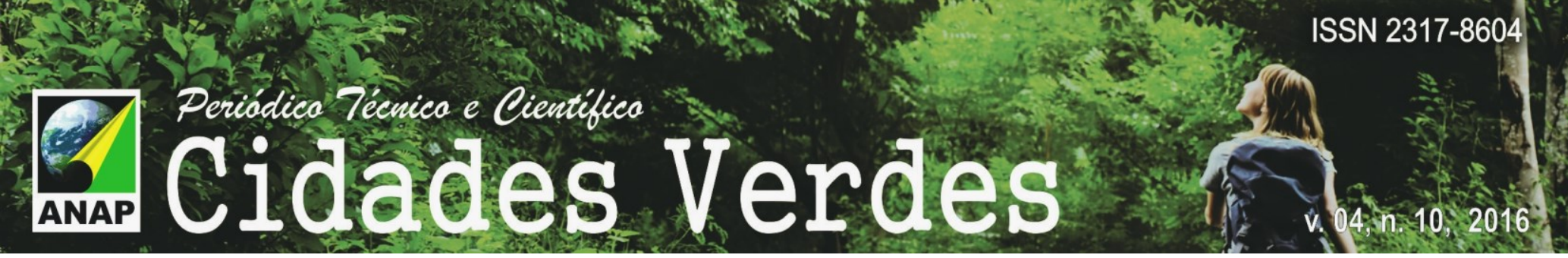

CRUZ, Marcus Aurélio Soares; ARAÚJO, Paulo Roberto; AGRA, Sidnei Gusmão; SOUZA, Vladimir Caramori Borges; COLLISCHOM, Walter. Valorização da Água no Meio Urbano: Um Desafio Possível. Porto Alegre, 2001.

GOOGLE EARTH. [Condomínio Tipuanas, Araraquara/SP];[Condomínio Parque Eco-Esportivo Damha, São Carlos/SP]. Acesso em: 08 set 2016.

MARICATO, Erminia. Globalização e política urbana na periferia do capitalismo. Territorios 18-19, Bogotá. Sección general, pag. 183-205, 2008.

NASCIMENTO, N. O.; BAPTISTA, M. B.; VON SPERLING, E. Problemas de Inserção Ambiental de Bacias de Detenção em Meio Urbano, in Anais do XX Congresso Brasileiro de Engenharia Sanitária e Ambiental, volume 29, Rio de Janeiro, 1999, pp. 2242-2250.

POMPÊO, César Augusto. Drenagem Urbana Sustentável. Revista Brasileira de Recursos Hídricos, Porto Alegre, v. 5, no 1, pag. 15-23, 2000.

PORTO, Rubem; ZAHED FILHO, Kamel; TUCCI, Carlos; BIDONE, Francisco. Drenagem Urbana. In: TUCCI, C. E. M.; SILVEIRA, A. L. L.;... [et al]. Hidrologia: ciência e aplicação. 4 ed. - Porto Alegre: Editora da UFRGS/ABRH. 2015. p. 805-847.

PORTO ALEGRE. Prefeitura Municipal. Detenção - as bacias que ficam secas. Disponível em:<http://www2.portoalegre.rs.gov.br/dep/default.php?p_secao=69>. Acesso em: 25 mai. 2016.

RIGHETTO, A. M. Manejo de Águas Pluviais. Rio de Janeiro: ABES, 2009. 396p.

TUCCI, Carlos E. M. Inundações Urbanas. In: TUCCI, C. E. M.; PORTO, R. La L.; BASTOS, M. T. Drenagem Urbana. Porto Alegre: ABRH, 2015. p. 15-36.

UNRIC: Centro Regional de Informação das Nações Unidas. Relatório da ONU mostra população mundial cada vez mais urbanizada, mais de metade vive em zonas urbanizadas ao que se podem juntar 2,5 mil milhões em 2050. Nova York, 10 jul. 2014. Disponível em: <http://www.unric.org/pt/actualidade/31537-relatorio-da-onu-mostrapopulacao-mundial-cada-vez-mais-urbanizada-mais-de-metade-vive-em-zonas-urbanizadas-ao-que-se-podemjuntar-25-mil-milhoes-em-2050>. Acesso em: 26 mai. 2016.

VICENTE, T. Z. Análise de uso, apropriação e integração urbana das técnicas compensatórias em drenagem urbana na cidade de Ribeirão Preto-SP. Dissertação (Mestrado em Engenharia Urbana) - Universidade Federal de São Carlos - UFSCar, 2015. 